\section{Does osteoporosis affect children and adolescents?}

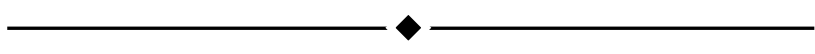

Dear Editor:

We read with great interest the article by Campos et al. on osteoporosis in childhood and adolescence, recently published in the Jornal de Pediatria. ${ }^{1}$ The article in question performed an excellent review of published literature, comprehensively contemplating the subject in an enlightening and objective manner. However, a small error is to be observed in the description of imaging methods, in particular DEXA (equipment with double emission of $X$ rays), where the authors indicate that bone mineral density (BMD) is expressed in $\mathrm{g} / \mathrm{cm}^{3}$. Bone mineral density evaluated by this method is expressed in $\mathrm{g} / \mathrm{cm}^{2}$, being the ratio between bone mineral content (BMC) in grams and total area (A) of the region being investigated, expressed in $\mathrm{cm}^{2}$.

Another issue of great interest raised by the authors was the focus on dietary guidance, perfectly structured and confirmed by other reports, including work that we will publish shortly. ${ }^{2}$ On the subject of physical activity we would point out that the term physiotherapy with weights would be better expressed by physical exercises with weights (strength training), already reported in literature reviews, ${ }^{3,4}$ relating sport to its implications for the bone health of adolescent athletes. ${ }^{5}$

With reference to the critical periods of bone mineral capital acquisition, Campos et al. ${ }^{1}$ describe intense mineralization during the first years of life and during adolescence (between 11 and 14 years for girls and 13 and 17 years among boys). A deep interest in the area led us to an investigation with male adolescents and the results indicated intense bone anabolism between the age group from 14 to 16 years and when they reach stage G4 of sexual maturity.

It was with great satisfaction that we write this letter to the authors of the aforementioned article, which offered us enlightenment and an opportunity to increase knowledge which we believe will be indispensable to the evolution of understanding of bone metabolism during childhood and adolescence, since, while the final clinical manifestations related to osteoporosis mainly occur during old age, predisposing factors are at work during childhood and adolescence, periods of maximum bone mineral capital take up.

\section{Tamara B. L. Goldberg}

PhD. Assistant professor, Department of Pediatrics, School of Medicine of Botucatu, Universidade Estadual Paulista (UNESP), Botucatu, SP, Brazil.

\section{Carla C. Silva}

Graduate student, Graduate Program in Pediatrics, School of Medicine of Botucatu, Universidade Estadual Paulista (UNESP), Botucatu, SP, Brazil.

\section{References}

1. Campos LMA, Liphaus BL, Silva CAA, Pereira RMR. Osteoporose na infância e adolescência. J Pediatr (Rio J). 2003;79:481-8.

2. Silva CC, Teixeira AS, Goldberg TBL. Impacto da ingestão de cálcio sobre a mineralização óssea em adolescentes. Rev Nutr. No prelo 2004.

3. American Academy of Pediatrics, Committee on Sports Medicine and Fitness. Strength training by children and adolescents. Pediatrics. 2001;107:1470-2.

4. Faigenbaum AD. Strength training for children and adolescents. Clin Sports Med. 2000;19:593-619.

5. Silva CC, Teixeira AS, Goldberg TBL. O esporte e suas implicações na saúde óssea de atletas adolescentes. Rev Bras Med Esporte. 2003;9:426-38.

\section{Authors' reply}

Dear Editor,

We are grateful for the comments made by Goldberg and Silva on our review "Osteoporosis in Childhood and Adolescence" 1 and would like to clarify some points related to them. As was described in our article, and commented on by two readers, bone mass is assessed in terms of bone mineral content (CMO, in grams) and mineral density (DMO, the ratio of CMO in grams to total area in $\mathrm{cm}^{2}$ ). Even when DMO $\left(\mathrm{g} / \mathrm{cm}^{2}\right)$ is adjusted for the area scanned, this does not correct for different bone thicknesses. Thus, particularly in children, the true bone mineral density is overestimated for large bones and underestimated for small ones. In attempts to avoid this problem, some authors have developed mathematical models for estimated bone volume $\left(\mathrm{cm}^{3}\right)$ instead of bone area $\left(\mathrm{cm}^{2}\right) \cdot{ }^{2-5}$ This method reduces the confounding effects of bone size. Carter et al. ${ }^{5}$ denominated this method "apparent bone mineral density" (ABMD, $\mathrm{g} / \mathrm{cm}^{3}$ ). Despite this methodology being apparently more correct, we end up using results from the densitometer in clinical practice and even in clinical research with normal children and adolescents 6,7 and those with chronic pathologies. The resultant bone mineral density is the ratio of CMO and the area of the region under analysis $\left(\mathrm{cm}^{2}\right)$.

Physical activity, especially exercises against gravity, should be one of the main recommendations for treatment and prevention of osteoporosis, principally in the pediatric age group, which is when peak bone mass is achieved. The authors of the review article in question agreed with the suggestion to use the term physical exercises with weights (strength training) instead of physiotherapy with weights. Strength training is an important stimulant of bone mass, although sometimes its use is limited by low age and pubertal stage and it should always be performed under professional supervision. While disagreement remains, other types of no-impact physical activity can also stimulate bone mass. Lima et al., ${ }^{7}$ in a study performed at the Rheumatology Department of FMUSP, studied the bone metabolism and body composition of three groups of male adolescent athletes: participants in activities involving impact, participants in no-impact activities and normal controls. 
The greatest levels of DMO were found in the group practicing exercises involving impact and even those adolescents who practiced no-impact activities exhibited superior DMO to the control group.

\section{References}

1. Campos LM, Liphaus BL, Silva CA, Pereira RM. Osteoporose na infância e adolescência. J Pediatr (Rio J). 2003;79:481-8.

2. Kroger $\mathrm{H}$, Kotaniemi A, Vainio $\mathrm{P}$, Alhava $\mathrm{E}$. Bone densitometry of the spine and femur in children by dual-energy $x$-ray absorptiometry. Bone Miner. 1992;17:75-85.

3. Bachrach LK. Osteoporosis in childhood and adolescence. In: Marcus R, Feldman D, Klesey J, editors. Osteoporosis. 2nd ed. San Diego:Academic Press; 2001. p.151-67.

4. Lu PW, Cowell CT, Loyd-Jones SA, Briody JN, Howman-Giles R. Volumetric bone mineral density in normal subjects, aged 5-27 years. J Clin Endocrinol Metab. 1996;81:1586-90.

5. Carter DR, Bouxsein ML, Marcus R. New approaches for interpreting projected bone densitometry data. J Bone Miner Res. $1992 ; 7: 137-45$

6. Pinto ALS, Takayama L, Carazzato JC, Pereira RMR, Lima FR. Bone density and body composition in adolescent female swimmers. Arthritis Rheum. 2000;43:S393.
7. Lima F, De Falco V, Baima J, Carazzato JG, Pereira RM. Effect of impact load and active load on bone metabolism and body composition of adolescent athletes. Med Sci Sports Exerc. 2001;33:1318-23.

8. Pereira RM, Corrente JE, Chahade WH, Yoshinari N. Evaluation by dual X-ray absorptiometry (DXA) of bone mineral density in children with juvenile chronic arthritis. Clin Exp Rheumatol. $1998 ; 16: 495-501$

\section{Lúcia M. A. Campos}

Master's Degree. Assistant physician, Division of Rheumatology, Children's Institute, Hospital das Clínicas, School of Medicine, Universidade de São Paulo (USP), São Paulo, SP, Brazil.

\section{Bernadete L. Liphaus}

Master's Degree. Assistant physician, Division of Rheumatology, Children's Institute, Hospital das Clínicas, School of Medicine, Universidade de São Paulo (USP), São Paulo, SP, Brazil.

\section{Clovis A. A. Silva}

PhD. Chief physician, Division of Rheumatology, Children's Institute, Hospital das Clínicas, School of Medicine, Universidade de São Paulo (USP), São Paulo, SP, Brazil.

Rosa M. R. Pereira

PhD. Assistant professor, School of Medicine, Universidade de São Paulo (USP). Chief of the Laboratory of Osteometabolic Diseases, Department of Rheumatology, School of Medicine, Universidade de São Paulo (USP), São Paulo, SP, Brazil. 